University of Massachusetts Amherst

ScholarWorks@UMass Amherst

Chemistry Department Faculty Publication Series

Chemistry

2007

\title{
Determination of selenium by flow injection hydride generation inductively coupled plasma optical emission spectrometry
}

PC Hernandez

JF Tyson

PC Uden

D Yates

Follow this and additional works at: https://scholarworks.umass.edu/chem_faculty_pubs

Part of the Chemistry Commons

\section{Recommended Citation}

Hernandez, PC; Tyson, JF; Uden, PC; and Yates, D, "Determination of selenium by flow injection hydride generation inductively coupled plasma optical emission spectrometry" (2007). Journal of Analytical Atomic Spectrometry. 1011.

Retrieved from https://scholarworks.umass.edu/chem_faculty_pubs/1011 


\title{
Determination of selenium by flow injection hydride generation inductively coupled plasma optical emission spectrometry ${ }^{\dagger}$
}

\author{
Received 1st September 2006, Accepted 20th November 2006 \\ First published as an Advance Article on the web 22nd December 2006 \\ DOI: $10.1039 / \mathrm{b612658h}$
}

Princess C. Hernandez, ${ }^{a}$ Julian F. Tyson, ${ }^{* a}$ Peter C. Uden ${ }^{a}$ and Dennis Yates ${ }^{b}$

Two flow injection hydride generation procedures for the determination of selenium with an inductively coupled plasma emission spectrometer capable of monitoring transient signals were developed. In one, the acidified sample was injected into an acid carrier, which merged downstream with a stream of thiourea (for samples containing significant concentrations of copper) then with a stream of borohydride. In the second, the analyte was preconcentrated by passing the sample through an on-line anion-exchanger, followed by elution of the retained selenium eluted with acid into the HG manifold. A systematic study was made of the effect of radiofrequency power, plasma gas flow, stripping gas flow, sodium borohydride and hydrochloric acid concentrations and flow rates, sample acidity and the lengths of mixing and stripping coils. The hydride was stripped from solution and transported to the plasma by the gas normally delivered to the nebulizer, through a direct connection between the gas-liquid separator and the injector tube. The limits of detection for the first method, which ranged from 0.7 to $0.3 \mu \mathrm{g} 1^{-1}$ for 200-1000 $\mu \mathrm{l}$ sample volumes, were 10 times lower than those for conventional nebulization. The reproducibility (relative standard deviation of 5 successive measurements) was between 2-5\% for $10 \mu \mathrm{g}^{-1}-100 \mu \mathrm{g}^{-1} \mathrm{Se}$ in $10 \% \mathrm{HCl}$. The repeatability, based on five measurements per day performed on three consecutive days, was $4-6 \%$ for $10 \mu \mathrm{g} \mathrm{l}^{-1}-100 \mu \mathrm{g} \mathrm{l}^{-1} \mathrm{Se}$. The overall procedure was validated by the determination of selenium in digests of spinach leaves (SRM 1570a), bovine liver (SRM 1577b) and dogfish muscles (DORM-2). The interference from copper was removed by the addition of thiourea at a confluence point in the FI manifold. In the second method, the detection limit was improved further so that for preconcentration for 2, 4 and 8 min at $8 \mathrm{ml} \mathrm{min}{ }^{-1}$, the limits of detection were 6,2 and $0.6 \mathrm{ng} \mathrm{l}^{-1}$, respectively. Improved tolerance to interfering ions due to the separation of the matrix was found for $\mathrm{Cl}^{-}, \mathrm{HCO}_{3}{ }^{-}, \mathrm{SO}_{4}{ }^{2-}, \mathrm{As}(\mathrm{v})$, $\mathrm{Cd}(\mathrm{II}), \mathrm{Co}(\mathrm{II}), \mathrm{Cu}(\mathrm{II}), \mathrm{Fe}(\mathrm{III}), \mathrm{Ni}(\mathrm{II})$ and $\mathrm{Sb}(\mathrm{III})$, although it was found that many of the metallic interfering species were partially retained. The post-column addition of $0.10 \%(\mathrm{w} / \mathrm{v})$ thiourea improved the tolerance towards $\mathrm{Cu}$ (II). Recoveries of selenium from a variety of water samples showed that the resulting procedure was free from interferences.

\section{Introduction}

Selenium is both beneficial and toxic to animals, plants, and humans. ${ }^{1}$ Its toxicity was recognized first: the conditions in animals known as 'alkali disease' and 'blind staggers' are manifestations of the chronic and acute states of selenosis. It was not until the late 1950s that selenium was discovered to be an essential nutrient. ${ }^{2}$ In the early 1970 s, Rotruck et al. found ${ }^{3}$ that selenium was a component of the enzyme glutathione peroxidase (GPX), present in cells in the cytosol and in the mitochondria. There are at least five GPX isoforms and at least four other proteins identified as specifically incorporating selenium. ${ }^{4}$ These selenoenzymes and selenoproteins are involved in the removal of hydrogen peroxide and lipid peroxides produced during oxidative processes in cells. In 1996,

\footnotetext{
${ }^{a}$ Department of Chemistry, University of Massachusetts, Amherst, MA 01002, USA

${ }^{b}$ PerkinElmer, Life and Analytical Sciences, Shelton CT 06484, USA $\dagger$ Presented at the 13th British National Atomic Spectoscopy Symposium (BNASS) held in Glasgow, UK, July 10-12, 2006.
}

Clark et al. reported $^{5}$ that dietary supplementation with selenized brewer's yeast decreased overall cancer morbidity and mortality by nearly $50 \%$.

Various techniques have been used to quantify the low concentrations of selenium typically found in environmental, biological and clinical materials. These techniques include AFS, ${ }^{6-10}$ AAS, ${ }^{1-13}$ ICP-MS, ${ }^{14-17}$ and ICP-OES. ${ }^{18-22}$ According to a recent review by $\mathrm{Pohl}^{23}$ for the relevant elements, continuous flow $\mathrm{HG}$ has been widely used as a sample introduction technique for OES because of the high analyte transport efficiency, and the possibilities for the elimination of spectral interferences since the analyte is separated from the matrix. In the FI mode, there is the additional benefit of increasing sample throughput, though this has not been so widely implemented as most of the current generation of instruments cannot handle timebased transient signals. However, it is clear from Pohl's review that there are still problems of chemical interference to be overcome, especially those due to the transition and noble metals. 
Dos Santos and co-workers developed a continuous chemical vapour generation system with ICP-OES to evaluate slurry preparation procedures for the simultaneous determination of $\mathrm{Hg}$ and Se in biological samples. ${ }^{24}$ The LOD for selenium was $0.1 \mu \mathrm{g} \mathrm{g}^{-1}$. Rubio et al. determined ${ }^{25}$ selenate and selenite after an LC separation by photoreduction-HG-ICP-OES. The LOD were $6.8 \mu \mathrm{g}^{-1}$ and $16 \mu \mathrm{g}^{-1}$ for selenite and selenate, respectively. Carrion and co-workers developed a new direct HG nebulizer (DHGN) system for ICP-OES with an LOD of $0.2 \mu \mathrm{g}^{-1} .^{26}$ The design was based on a $\mathrm{V}$-groove Babingtontype nebulizer with a $120 \mu \mathrm{m}$ gas orifice and two solution input channels. The DHGN showed better analytical performance for the determination of $\mathrm{As}, \mathrm{Sb}$ and $\mathrm{Se}$ compared with that of conventional nebulization systems. ${ }^{27}$ Recently, McLaughlin and Brindle have reported a sample introduction system for ICP-OES known as the Multimode Sample Introduction System $^{\mathrm{TM}}$ (MSIS $^{\mathrm{TM}}$ ) that can be used for continuous nebulization and hydride generation. ${ }^{28}$ In the HG mode, MSIS LOD were decreased by 10-90 fold compared with those for conventional nebulization.

Many studies have been focused on improving methodologies to measure selenium in low concentrations. In a recent review, Evans et al. described ${ }^{29}$ preconcentration as one of the most widely used pre-treatment methods in the determination of Se. Preconcentration by solid-phase extraction is popular because of its ability to separate the desired analyte from the interfering matrix as well as increase the mass flux to the spectrometer. Wake et al. ${ }^{30}$ have reviewed preconcentration methods in the determination of selenium species in natural waters and cited some 19 papers in which solid-phase extraction was the procedure of choice. Several researchers have reported the on-line preconcentration of selenite using strong anion-exchange (SAX) materials. ${ }^{31-33}$ Carrero and Tyson devised $^{34}$ a unique on-line preconcentration and hydride generation procedure for the determination of Se. They retained simultaneously selenium as selenite, Se(Iv), and tetrahydroborate(III) on an SAX, Amberlite IRA-410. The $\mathrm{H}_{2} \mathrm{Se}$, generated by the passage of a discrete volume of acid, was detected by AAS with quartz tube atomization. Preconcentration procedures with polytetrafluoroethylene fibres ${ }^{35}$ and porous graphitic carbon ${ }^{36}$ have been developed. Procedures for the simultaneous determination of both inorganic and organic selenium species based on selective retention on anion-exchangers have been devised. ${ }^{37,38}$ Offley and co-workers decreased copper interferences in the determination of selenium by HGAAS by retention of the copper on a strong cation-exchange (SCX) resin, ${ }^{39}$ whereas Moyano et al. ${ }^{40}$ retained copper chlorocomplexes on an anion-exchange resin, and Martinez et al. ${ }^{19}$ removed the interference by iron in a similar fashion.

In this paper, we describe two methods for the determination of selenium in which the hydride is generated in a FI manifold (a PerkinElmer FIAS 400 unit) and introduced to an ICP-OES instrument (a PerkinElmer Optima 4300DV with version 3.0 of PE Winlab32 ICP software) capable of monitoring time-based transient signals, as well as the normal wavelength-based transients obtained with steady-state sample introduction. Our results show that the procedures can be applied to the determination of selenium in biological matrices and natural waters, in the latter case at single-digit ng $1^{-1}$ concentrations. The detection limits achievable are improved by several orders of magnitude over those obtained by direct nebulization. Our report also describes a new solid-phase extraction material, the Discovery strong anion-exchanger from Supelco, which was particularly effective at retaining selenite, and from which the selenite could be released by the acid solution needed for the best HG performance. We show that the beneficial releasing agent action of thiourea can be exploited by adding the thiourea on-line. Thiourea cannot be added to the sample as it reduces selenium to the element, ${ }^{41}$ and a severely decreased signal is obtained. The first method was validated by the determination of selenium in digests of Spinach Leaves (SRM 1570a), Bovine Liver (SRM 1577b) and Dogfish Muscle (DORM-2). In the second method the LOD was improved by preconcentration by solid-phase extraction, allowing the determination of low $\mathrm{ng}^{-1}$ concentrations of selenium in spring, river, lake, and sea-waters.

\section{Experimental}

\section{Instrumentation}

Measurements were made with an inductively coupled plasma optical emission spectrometer (Model Optima 4300DV, PerkinElmer, Shelton, CT, USA), containing a segmented array charged coupled device (SCD) detector, fitted with a quartz torch and $2.0 \mathrm{~mm}$ id alumina injector tube. The ICP operating parameters, optimized for the measurement of Se by continuous flow hydride generation, are shown in Table 1.

Chemical vapour was generated in a flow injection analyser (Model FIAS 400, PerkinElmer) containing a glass gas-liquid separator (PerkinElmer Part No. B0193772). The pump head rotation speeds and valve actuation were under computer control (Winlab32 software version 3.0 for ICP, PerkinElmer), which also collected and displayed the time-based signal. The flow injection manifold is shown schematically in Fig. 1. The manifold was slightly changed when thiourea was used during

Table 1 FI-HG-ICP-OES operating procedures

\begin{tabular}{ll}
\hline ICP instrumental parameters & \\
\hline Rf generator power & $1450 \mathrm{~W}$ \\
Plasma gas flow rate & $161 \mathrm{~min}^{-1}$ \\
Auxiliary gas flow rate & $0.21 \mathrm{~min}^{-1}$ \\
Nebulizer gas flow rate & $0.51 \mathrm{~min}^{-1}$ \\
$\quad$ (stripping gas) & Axial \\
Viewing mode & $15 \mathrm{~mm}$ \\
Torch viewing position & $100 \mathrm{~ms}$ \\
Integration time & \\
The selenium spectral line of & \\
196.026 nm was used & \\
throughout & \\
& \\
Hydride generation parameters & $0.30 \%(\mathrm{w} / \mathrm{v}) \mathrm{NaBH}$ \\
NaBH in \\
& $0.05 \%(\mathrm{w} / \mathrm{v}) \mathrm{NaOH}$ \\
NaBH $\mathrm{Na}_{4}$ flow rate & $4.0 \mathrm{ml} \mathrm{min}-1$ \\
HCl solution & $10 \%(\mathrm{v} / \mathrm{v}) \mathrm{HCl}$ \\
HCl flow rate & $5.0 \mathrm{ml} \mathrm{min}{ }^{-1}$ \\
Sample acidity & $10 \%(\mathrm{v} / \mathrm{v}) \mathrm{HCl}$ \\
Mixing coil & $1000 \mathrm{~mm} \mathrm{length}, 1.0 \mathrm{~mm}$ id \\
Stripping coil & $275 \mathrm{~mm} \mathrm{length,} 1.0 \mathrm{~mm}$ id \\
\hline
\end{tabular}




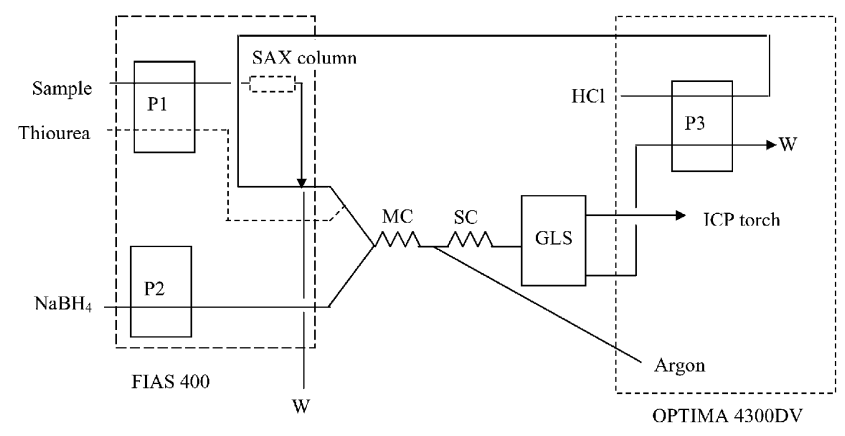

Fig. 1 Schematic diagram of the flow injection system for HGICP-OES.

the interference study. The acidified sample was allowed to mix with thiourea in another reaction coil before mixing with sodium borohydride. During the preconcentration experiment, a preconcentration column replaced the sample loop. PerkinElmer $1.52 \mathrm{~mm}$ id yellow/blue (Part No. B0193161) and $1.14 \mathrm{~mm}$ id red/red (Part No. B0193160) pump tubings were used for sample loading and borohydride flow. A Fisherbrand yellow/blue pump tubing (Catalog No. 14-190-118) was used for acid reagent flow. The argon stripping/carrier gas was the "nebulizer" gas delivered via the spectrometer and controlled by the Winlab32 software. The FIAS unit gas handling features were not used. Data were exported to Microsoft Excel as .CSV files and then to Microcal Origin 6.0 (Microcal Software, Inc., Northampton, MA, USA) for the generation of graphs. A MDS 2100 microwave oven (CEM, NC, USA) with PTFE vessels was used for the closed vessel microwaveassisted acid digestion.

\section{Reagents}

The selenium stock standard solution $\left(1000 \mu \mathrm{g}^{-1}\right)$ was a PE Pure Atomic Spectroscopy Standard (PerkinElmer). Sodium tetrahydridoborate, 98\% pure, was from AlfaAesar (Ward Hill, MA, USA), sodium hydroxide, AR grade, was from Mallinckrodt Baker Inc. (Paris, KY, USA) and hydrochloric acid, ACS Plus grade, was from Fisher Scientific (Fair Lawn, NJ, USA). Various concentrations of borohydride in $0.05 \%$ $(\mathrm{m} / \mathrm{v})$ were prepared, as were a range of hydrochloric acid concentrations. The Discovery strong anion-exchange resin was obtained from Supelco. Atomic absorption standards used in the interference study were antimony (Fisher Scientific, Fair Lawn, NJ, USA), arsenic (PE Pure Atomic Spectroscopy Standards), cadmium (Aldrich Chemicals Co., Inc., WI, USA), cobalt (Specpure, AlfaAesar, Ward Hill, MA, USA), copper (Spectrum Chemical Mfg. Corp., Gardena, CA, USA), iron (Fisher Scientific), and nickel (Fisher Scientific). The interfering anions were prepared from the following: anhydrous sodium sulfate, GPR grade, from BDH Chemicals Ltd. (Poole, Dorset, England), sodium chloride, certified ACS, from Fisher Scientific, and sodium bicarbonate, AR grade, from Mallinckrodt Baker. The masking agent used was thiourea, practical grade, from Kodak (Rochester, NY, USA). All glassware was washed with nitric acid and rinsed with ultra-pure water (18 M $\Omega$ Barnstead L-pure, Boston, MA, USA), which was used throughout the experiments.

\section{Sample digestion}

The standard reference material (SRM) digests were prepared by microwave digestion. Samples were digested by adding $2 \mathrm{ml}$ of $\mathrm{HNO}_{3}$ and $1 \mathrm{ml}$ of $\mathrm{H}_{2} \mathrm{O}_{2}$ to $200 \mathrm{mg}$ of the sample in a Teflon vessel. Becker has shown ${ }^{42}$ that biological reference materials can be homogeneous at sample masses as low as $1 \mathrm{mg}$. The vessels were sealed, left to stand for $1 \mathrm{~h}$, vented and then heated in an MDS 2100 Microwave oven. The microwave conditions (program A) for the digestion of the spinach leaves (SRM 1570a) are shown in Table 2. ${ }^{29}$ The spinach digests were diluted to $25 \mathrm{ml}$. An internally programmed procedure in the instrument specifically for liver samples (program B) was used for the digestion of the bovine liver (SRM 1577b) and dogfish muscle (DORM-2) (Table 2). SRM 1570a and DORM-2 digests were diluted to $50 \mathrm{ml}$. To ensure that all selenium species were in the form of selenite $\left(\mathrm{SeO}_{3}{ }^{2-}\right), 3.0 \mathrm{ml}$ of a $6 \mathrm{M}$ $\mathrm{HCl}$ solution was added to the digest and the resulting solution heated at $98{ }^{\circ} \mathrm{C}$ for 60 min. ${ }^{8}$ Samples were diluted to $10 \mathrm{~mL}$ in calibrated flasks.

\section{Method development}

FI-HG-ICP-OES. The instrument and FIAS operating conditions were all optimized while using continuous flow HG. The figure of merit was the best signal to noise ratio for the introduction of hydrogen selenide, with the boundary condition that values of parameters that produced a flickering or unstable plasma were considered sub-optimal. The various parameters were varied according to the multi-cycle alternating variable procedure, ${ }^{43}$ in which all parameters are varied one at a time in turn, followed by a second and, possibly a third iteration of the process. The parameters studied included (a) plasma parameters of power and gas flow rates and (b) FI parameters of borohydride and acid concentrations, borohydride and acid flow rates, argon flow rate, mixing coil and stripping coil lengths and injection volume. Sodium borohydride concentrations ranging from 0.05 to $0.50 \%(\mathrm{w} / \mathrm{v})$ were

Table 2 Microwave digestion program A (columns 1-5), and program B (columns 5-9)

\begin{tabular}{lllllllll}
\hline & 1 & 2 & 3 & 4 & 5 & 6 & 7 & 8 \\
\hline Power $(\%)^{a}$ & 25 & 66 & 66 & 66 & 25 & 100 & 100 & 0 \\
Pressure $\mathrm{psi}$ & 20 & 40 & 85 & 90 & 20 & 75 & 150 & 20 \\
Time $/$ min & 2 & 5 & 5 & 5 & 10 & 10 & 100 \\
Temperature $/{ }^{\circ} \mathrm{C}$ & 120 & 140 & 160 & 180 & 100 & 190 & 190 & 20 \\
${ }^{a} 1000 \mathrm{~W}$ full power. & & & & & & & & \\
\hline
\end{tabular}


used during optimization. A range of $\mathrm{HCl}$ concentrations from 1.0 to $15 \%(\mathrm{v} / \mathrm{v})$ was investigated. Sodium borohydride and hydrochloric acid flow rates were also studied. A unique feature of the manifold is that the argon is the 'nebulizer' gas, which can be controlled by the Winlab32 version 3.0 software. The effects of different lengths of the $1.0 \mathrm{~mm}$ id mixing and stripping coils over the range 135-1000 mm were also investigated.

Under the optimum conditions, analytical figures of merit and the recoveries of $\mathrm{Se}$ (Iv) from tap and sea-water were measured. The effect of sample volume on LOD was evaluated. Repeatability (within run precision) and reproducibility (between day precision) were measured. The analyses of the SRM (Spinach Leaves, Bovine Liver and Dogfish Muscle) indicated that both suppressions and enhancements of the signal by the residual matrix caused inaccuracies that could be overcome by calibration with the standard additions method. For these analyses, previously published microwave digestion $^{29}$ and oxidation state adjustment (pre-reduction) ${ }^{8}$ procedures were used. The heating time during pre-reduction was increased from 50 to 60 min to ensure complete conversion of $\mathrm{Se}(\mathrm{VI})$ to $\mathrm{Se}(\mathrm{IV})$. The effects of several transition metals and hydride-forming elements were studied and the possible benefits of the addition of thiourea investigated.

\section{Solid-phase extraction}

Preconcentration parameters including sample loading flow rate and sample loading time were optimized under the FI-HG-ICP-OES parameters in Table 1. The effect of preconcentration flow rate was studied by loading $10 \mathrm{ml}$ of a $1 \mu \mathrm{g}$ $1^{-1}$ Se standard at different flow rates. The flow rate was increased from 2 only up to $8.0 \mathrm{ml} \mathrm{min} \mathrm{m}^{-1}$ due to the limitation of pump speed and availability of pump tubings. Preconcentration time was also studied and varied while loading $1 \mu \mathrm{g}^{-1}$ Se standard at $8.0 \mathrm{ml} \mathrm{min}{ }^{-1}$. The programmed sequence used for preconcentration is given in Table 3. Pump 1 was used for sample loading while pump 2 was used for continuous flow of borohydride. A $25 \mathrm{~mm} \times 3.3 \mathrm{~mm}$ id glass column obtained from OmniFit was packed with Discovery SAX resin. Highpressure argon was passed through the column to ensure uniform packing. Since the particle size of the resin was very small, two small pieces of glass wool were inserted in both ends of the column. The column contained $0.07 \pm 0.02 \mathrm{~g}$ $(95 \% \mathrm{CI})$ of resin. Selenium in the form of selenite, $\mathrm{SeO}_{3}{ }^{2-}$, was trapped in the column and then eluted with the carrier acid. The sample loading time and flow rate were investigated. The effect of sample-loading time (120, 240, and $480 \mathrm{~s}$ ) was studied. The effect of $\mathrm{pH}$ on analyte retention was also investigated.

Table 3 Programmed sequence for the FIAS unit

\begin{tabular}{lllll}
\hline Step & Time/s & Pump 1 & Pump 2 & Position \\
\hline Prefill & 3 & 120 & 85 & Fill \\
1 & 60 & 120 & 85 & Fill \\
2 & 60 & 120 & 85 & Fill \\
3 & 45 & 0 & 85 & Inject \\
\hline
\end{tabular}

\section{Method validation}

The procedure was validated by the determination of selenium in digests of Spinach Leaves (SRM 1570a), Bovine Liver (SRM 1577b) and Dogfish Muscle (DORM-2). The effects of interfering ions were investigated. Transition elements including cobalt, copper, iron and nickel and hydride forming elements, such as antimony and arsenic, were studied. A

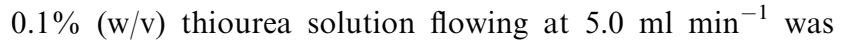
mixed with the acid carrier in a second mixing coil $(300 \mathrm{~mm}$, $0.5 \mathrm{~mm}$ id) prior to the addition of sodium borohydride. The flow rate and concentration of the thiourea solution were optimized.

The preconcentration method was validated by measurement of the recovery of low $n g 1^{-1}$ concentrations of Se in different water samples. Spring water (Brentwood, NH), river water (Connecticut River), and lake water (Otis Big Pond, MA) samples were spiked with $50 \mathrm{ng}^{-1} \mathrm{Se}$, while the seawater (Newport, RI) was spiked with $500 \mathrm{ng}^{-1}$ Se. Samples were filtered $(0.45 \mu \mathrm{m})$ prior to analysis. The effect of varying concentrations of interfering ions was also investigated. A 100 -ml volume of a $100 \mathrm{ng}^{-1}$ solution of Se(IV) was spiked with the interfering ion and then measured by FI-HG-ICPOES. In preliminary experiments, a high copper concentration decreased the sensitivity, and so a $0.1 \%(\mathrm{w} / \mathrm{v})$ thiourea in $10 \%$ $(\mathrm{v} / \mathrm{v}) \mathrm{HCl}$ solution was used as eluent. Thiourea cannot be added to the sample as it reduces $\mathrm{Se}(\mathrm{Iv})$ to the elemental state. $^{41}$

\section{Results and discussion}

\section{Optimization of parameters for Se hydride generation}

Under some conditions of reagent concentration and flow rates, sufficient hydrogen was produced to destabilize the plasma, resulting in observable flicker and extinction. The optimum conditions were: borohydride concentration of

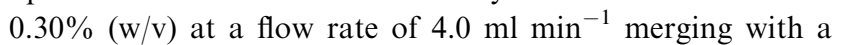
$10 \%(\mathrm{v} / \mathrm{v}) \mathrm{HCl}$ solution flowing at $5.0 \mathrm{ml} \mathrm{min}^{-1}$.

\section{FI-HG-ICP-OES figures of merit and validation}

Detection limits and precision were measured under the optimum conditions. The peak area LODs $(3 s)$ for $200 \mu \mathrm{L}$, $500 \mu \mathrm{L}$ and $1000 \mu \mathrm{L}$ sample loops were $0.7,0.7$ and $0.3 \mu \mathrm{g}^{-1}$, respectively. The corresponding peak height values were 0.4 , 0.3 and $0.2 \mu \mathrm{g}^{-1}$. The LODs were at least 10 times better than the value for conventional nebulization, and are comparable with those previously reported. ${ }^{20,24,40}$ The reproducibility, determined from five measurements per day performed on three consecutive days, was $4-6 \%$ over the range $10 \mu \mathrm{g}^{-1}$ to $100 \mu \mathrm{g} \mathrm{l}^{-1} \mathrm{Se}$. The repeatability (RSD of 5 successive measurements) was between $2-5 \%$ over the range $10 \mu \mathrm{g} 1^{-1}-100 \mu \mathrm{g} 1^{-1}$ Se. The calibration was linear up to $1000 \mu \mathrm{g}^{-1}$, above which detector saturation occurred. The new PerkinElmer version 3.0 Winlab32 software allows the transient peaks, examples of which are shown in Fig. 2, to be viewed directly during the analysis. This is a useful diagnostic tool, as a deviation from the expected peak shape is an indicator of a problem. 


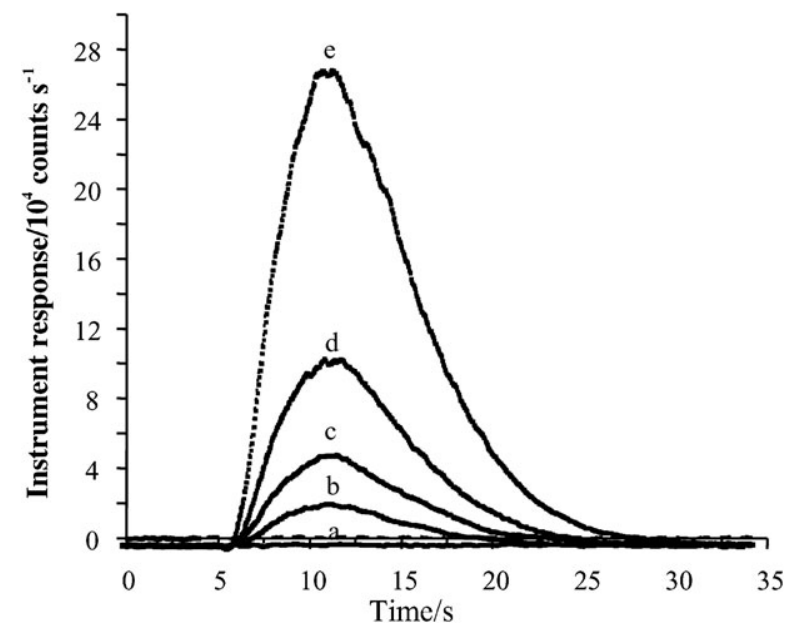

Fig. 2 Transient responses to different Se concentrations determined by FI-HG-ICP-OES: (a) $0 \mu \mathrm{g} \mathrm{l}^{-1} \mathrm{SeO}_{3}{ }^{2-}$; (b) $25 \mu \mathrm{g} \mathrm{l}^{-1} \mathrm{SeO}_{3}{ }^{2-}$; (c) $50 \mu \mathrm{g} \mathrm{l}^{-1} \mathrm{SeO}_{3}{ }^{2-}$; (d) $100 \mu \mathrm{g} \mathrm{l}^{-1} \mathrm{SeO}_{3}{ }^{2-}$; and (e) $250 \mu \mathrm{g} \mathrm{l}^{-1} \mathrm{SeO}_{3}{ }^{2-}$.

The results for the analyses of the SRM are given in Table 4. The means of the certificate values fall within the $95 \%$ confidence intervals of the measured values for all three SRM.

\section{FI-HG-ICP-OES interference studies}

It was found that thiourea was more effective as a masking reagent when added at a merging point (as shown by the dotted line in Fig. 1) than when added to the acid carrier. The complete removal of the interference of $25 \mathrm{mg} \mathrm{l}^{-1} \mathrm{Cu}$ (II) on $5 \mu \mathrm{g}^{-1} \mathrm{Se}(\mathrm{Iv})$ is shown in Fig. 3. This is a simpler procedure than previously described methods in which the copper was removed by retention on an ion-exchanger. ${ }^{39,40}$ The tolerance towards other elements is shown in Table 5.

\section{Optimization of preconcentration procedure}

As the relatively small particle size of the Discovery SAX resin $(56 \mu \mathrm{m})$ resulted in high back-pressure the column length was limited to $25 \mathrm{~mm}$. Investigations of the effect of flow rate showed that the resin efficiently adsorbed the analyte at flow

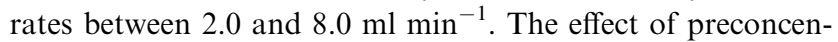
tration time was studied at $8.0 \mathrm{ml} \mathrm{min} \mathrm{m}^{-1}$; it was found that the amount of Se trapped increased linearly with time up to $10 \mathrm{~min}$. Retention was not affected over the $\mathrm{pH}$ range of 3-8.

Table 4 Determination of Se in certified reference materials

\begin{tabular}{lccc}
\hline & & \multicolumn{2}{l}{$\begin{array}{l}\text { Calculated concentration/ } \\
\mu \mathrm{g} \mathrm{g}^{-1} \pm 95 \% \mathrm{CI}\end{array}$} \\
\cline { 3 - 4 } Sample & $\begin{array}{l}\text { Certified } \\
\text { concentration } / \mu \mathrm{g} \mathrm{g}^{-1}\end{array}$ & Peak area & Peak height \\
\hline SRM 1570a & $0.117 \pm 0.009$ & $0.101 \pm 0.020^{a}$ & $0.134 \pm 0.030^{a}$ \\
SRM 1577b & $0.73 \pm 0.06$ & $0.65 \pm 0.10^{b}$ & $0.86 \pm 0.33^{b}$ \\
DORM-2 & $1.40 \pm 0.09$ & $1.29 \pm 0.45^{b}$ & $1.20 \pm 0.53^{b}$ \\
${ }^{a} n=5 .{ }^{b} n=3$. & & \\
\hline
\end{tabular}

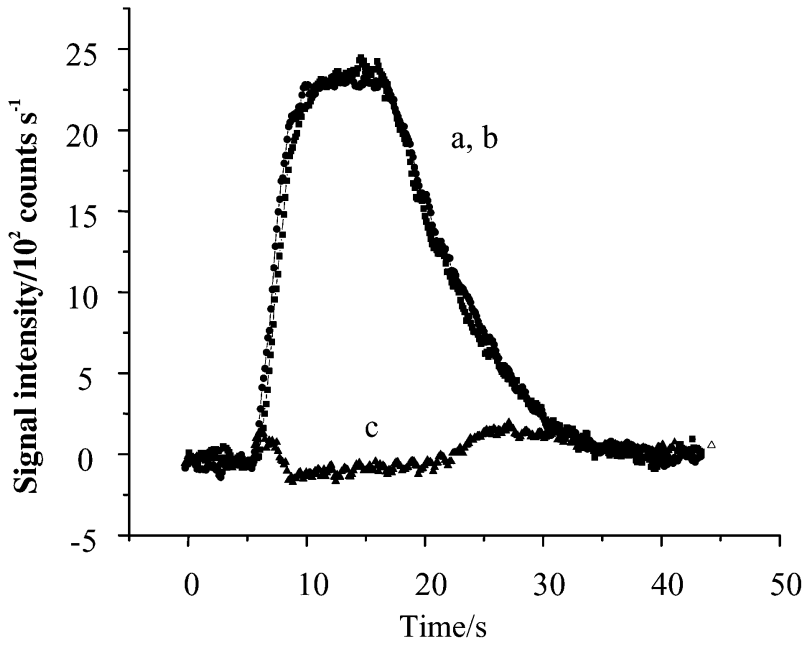

Fig. 3 Effect of thiourea on the determination of Se in the presence of copper. Curve a, $5 \mathrm{ng} \mathrm{ml}^{-1}$ selenium; curve b, $5 \mathrm{ng} \mathrm{ml}^{-1}$ selenium and $25 \mu \mathrm{g} \mathrm{ml}^{-1}$ copper with thiourea solution added at a merging point; and curve c, $5 \mathrm{ng} \mathrm{ml}^{-1}$ selenium and $25 \mu \mathrm{g} \mathrm{ml}^{-1}$ copper with thiourea added to the acid stream.

\section{Preconcentration figures of merit and validation}

The peak area LOD for $120 \mathrm{~s}, 240 \mathrm{~s}$, and $480 \mathrm{~s}$ loading times were 10,10 , and $1.0 \mathrm{ng} \mathrm{l}^{-1}$, respectively, while the corresponding peak height values were $6.3,2.3$, and $0.6 \mathrm{ng}^{-1}$. These values are 2-3 orders of magnitude better than those obtained without preconcentration and comparable to that obtained using ICP-MS with direct nebulization. It is not immediately clear why the improvement should be as large as this, as the volume processed is between 1 and 2 orders of magnitude greater. The eluted peaks were sharper than the injected peaks as the selenium is eluted at the front of the zone and this will give rise to an improved SNR as (a) the peak height is increased and (b) the integration window includes less background. The peak height enhancement factor was 48 . The precision of the method ranged between $0.6-3.0 \%$ RSD. For a sample loading time of $120 \mathrm{~s}$, a linear response $(r=0.992)$ was obtained up to $25 \mu \mathrm{g}^{-1}$, above which the detector became saturated. As this concentration is well above the LOD for HG without preconcentration, detector saturation should not be an issue.

\section{Preconcentration interference studies}

Initial studies of the recoveries from various water samples showed that the presence of other anions, such as $\mathrm{Cl}^{-}, \mathrm{HCO}_{3}{ }^{-}$ and $\mathrm{SO}_{4}{ }^{2-}$ could substantially decrease the retention of $\mathrm{SeO}_{3}{ }^{2-}$. The capacity of the resin, according to the manufacturer, is 0.14 mequiv $\mathrm{g}^{-1}$, and thus the column has a capacity of up to about $10 \mu$ equiv. For a singly charged species of molar mass 80 , this corresponds to $800 \mu \mathrm{g}$, although the capacity is likely to less under the high flow conditions of these experiments. The effect of loading time when these other anions were present is shown in Fig. 4, from which it can be seen that at longer preconcentration times the selectivity for $\mathrm{SeO}_{3}{ }^{2-}$ was decreased, and that sulfate was the major competing anion. For $120 \mathrm{~s}$ loading time, no significant decrease in Se sensitivity 
Table 5 Relative signal for Se in the presence of interfering ions

\begin{tabular}{|c|c|c|c|c|c|c|}
\hline \multirow{2}{*}{$\begin{array}{l}\text { Interfering } \\
\text { element }\end{array}$} & \multirow{2}{*}{$\begin{array}{l}\text { Concentration of } \\
\text { interferent } / \mu \mathrm{g} 1^{-1} \text {. } \\
\text { No preconcentration } \\
5 \mu \mathrm{g}^{-1} \mathrm{Se}\end{array}$} & \multirow{2}{*}{$\begin{array}{l}\text { Concentration of } \\
\text { interferent } / \mu \mathrm{g}^{-1} \text {. } \\
\text { Preconcentration } \\
100 \mathrm{ng} \mathrm{l}^{-1} \mathrm{Se}\end{array}$} & \multicolumn{2}{|c|}{$\begin{array}{l}\text { Relative signal }(\%)(95 \% \text { CI, } \\
n=4) . \text { No preconcentration }\end{array}$} & \multicolumn{2}{|c|}{$\begin{array}{l}\text { Relative signal }(\%)(95 \% \mathrm{CI} \text {, } \\
n=5) . \text { Preconcentration }\end{array}$} \\
\hline & & & Peak area & Peak height & Peak area & Peak height \\
\hline $\mathrm{As}(\mathrm{III})$ & $2.5 \times 10^{3}$ & - & $103 \pm 6$ & $100 \pm 4$ & - & - \\
\hline $\mathrm{As}(\mathrm{v})$ & - & 50 & - & - & $96 \pm 12$ & $91 \pm 3$ \\
\hline $\mathrm{Cd}(\mathrm{II})$ & - & 75 & - & - & $96 \pm 11$ & $97 \pm 3$ \\
\hline $\mathrm{Co}(\mathrm{II})$ & $5.0 \times 10^{6}$ & 500 & $97 \pm 7$ & $97 \pm 6$ & $92 \pm 7$ & $88 \pm 5$ \\
\hline $\mathrm{Cu}(\mathrm{II})$ & $2.5 \times 10^{4}$ & 50 & $107 \pm 8$ & $104 \pm 4$ & $101 \pm 11$ & $97 \pm 5$ \\
\hline $\mathrm{Fe}(\mathrm{III})$ & $1.0 \times 10^{5}$ & 50 & $102 \pm 13$ & $105 \pm 11$ & $94 \pm 9$ & $92 \pm 3$ \\
\hline $\mathrm{Ni}(\mathrm{II})$ & $2.5 \times 10^{6}$ & 1000 & $125 \pm 9$ & $112 \pm 7$ & $93 \pm 3$ & $94 \pm 2$ \\
\hline $\mathrm{Sb}(\mathrm{III})$ & $2.5 \times 10^{3}$ & 50 & $98 \pm 10$ & $101 \pm 5$ & $100 \pm 13$ & $105 \pm 5$ \\
\hline
\end{tabular}

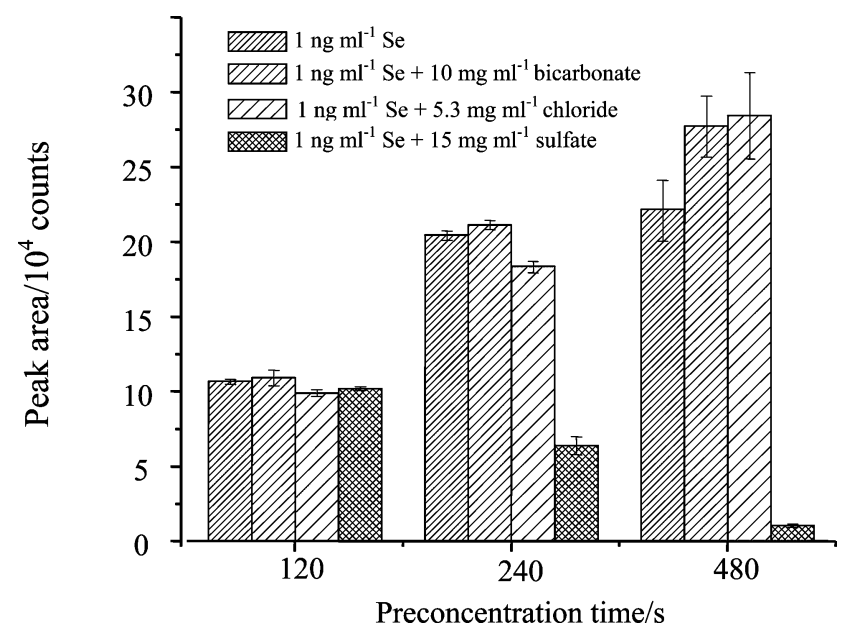

Fig. 4 Response for $1.0 \mu \mathrm{g} \mathrm{l^{-1 }}$ Se in the presence of different anions. The preconcentration flow rate was $8.0 \mathrm{ml} \mathrm{min}^{-1}$, the reductant flow rate was $4.0 \mathrm{ml} \mathrm{min}^{-1}$ and the acid carrier flow rate was $5.0 \mathrm{ml} \mathrm{min}{ }^{-1}$.

Table 6 Recovery of selenium from different water samples

\begin{tabular}{llr}
\hline & \multicolumn{2}{l}{ Recovery $(\%)^{a}$} \\
\cline { 2 - 3 } & Peak height & Peak area \\
\hline Spring water & $104 \pm 2$ & $90 \pm 11$ \\
River water & $101 \pm 4$ & $112 \pm 22$ \\
Lake water & $97 \pm 17$ & $98 \pm 56$ \\
Sea-water & $94 \pm 10$ & $120 \pm 81$ \\
${ }^{a}$ At $95 \% \mathrm{CI}, n=3$. & & \\
\hline
\end{tabular}

was observed in the presence of $15 \mathrm{mg} \mathrm{l}^{-1}$ sulfate and further studies of spike recoveries were made at this loading time. The percent recoveries from spring, river, and lake water samples spiked with $50 \mathrm{ng} \mathrm{l}^{-1} \mathrm{Se}$, and sea-water spiked with $500 \mathrm{ng}^{-1}$ $\mathrm{Se}$ are given in Table 6. The values ranged from 94 to $104 \%$ and 90 to $120 \%$ based on peak height and peak area measurements, respectively. Although it appears that the recoveries from the lake water and sea-water had larger confidence intervals about the means than the spring and river waters (possibly indicating that the matrix interferences were more severe than for the other water samples), the differences in standard deviations these values represent are not significant at the $95 \%$ confidence level based on a one-sided $F$-test. The procedure has the same limitations as other HG procedures for analyzing untreated waters in that samples may contain analyte species that (a) are not retained or (b) are retained and eluted, but are not borohydride active.

In a preliminary study of the effect of copper on $\mathrm{Se}$ preconcentration and hydride generation it was found that for $100 \mathrm{ng}^{-1}$ Se solution spiked with $50 \mu \mathrm{g} \mathrm{l^{-1 }} \mathrm{Cu}$ (II), a $69 \%$ depression of Se signal was obtained, indicating that some copper is retained on the column and co-eluted with the selenium. This suppression was removed when a thiourea solution was merged with the column eluent, as shown in Fig. 1. Other "cationic" species also interfered, as can be seen from Table 5, which shows the percent relative signal for $100 \mathrm{ng}^{-1} \mathrm{Se}$ in the presence of different interfering ions, including the other hydride-forming elements arsenic and antimony. The concentrations of interfering ions shown are approximately the highest tolerable. The results indicate that the determination of $\mathrm{ng}^{-1}$ concentrations of Se is possible in the presence of interfering ions whose concentrations are 500 times higher than that of the analyte.

\section{Acknowledgements}

This work was supported in part by the National Science Foundation under grant No. 0094568 (J.F.T.). We thank PerkinElmer Life Analytical Sciences for provision of the Optima 4300 DV spectrometer and FIAS 400 flow injection analyser. We also thank Supelco for the donation of the Discovery SAX resin.

\section{References}

1 J. M. M. Neil and L. S. Balistrieri, 'Geochemistry and Occurrence of Selenium: An Overview', in Selenium in agriculture and the environment, ed. L. W. Jacobs, American Society of Agronomy, Inc. and Soil Science Society of America, Inc., Wisconsin, 1989, pp. $1-13$.

2 K. Schwarz and C. M. Foltz, J. Am. Chem. Soc., 1957, 79, 32923293.

3 J. T. Rotruck, H. E. Ganther, A. B. Swanson, D. G. Hafeman and W. G. Hoekstra, Science, 1972, 179, 588-590.

4 G. F. Combs, Br. J. Nutr., 2001, 85, 517-547.

5 L. C. Clark, G. F. Combs, B. W. Turnbull, E. H. Slate, D. K. Chalker, J. Chow, L. S. Davis, R. A. Glover, G. F. Graham, E. G. Gross, A. Krongrad, J. L. Lesher, K. Park, B. B. Sanders, C. L. Smith and R. Taylor, J. Am. Med. Assoc., 1996, 276, 1957-1985. 
6 S. J. Hill, L. Pitts and P. Worsfold, J. Anal. At. Spectrom., 1995, 10, 409-441.

7 D. W. Bryce, A. Izquierdo and M. D. Luque de Castro, J. Anal. At. Spectrom., 1995, 10, 1059-1063.

8 M. E. Morena, C. Perez-Conde and C. Camara, J. Anal. At. Spectrom., 2000, 15, 681-686.

9 K. Marcucci, R. Zamboni and A. D'Ulivo, Spectrochim. Acta, Part B, 2001, 56, 393-407.

10 E. Dumont, K. De Cremer, M. Van Hulle, C. C. Chery, F. Vanhaecke and R. Cornelis, J. Anal. At. Spectrom., 2004, 19, 167-171.

11 A. Chatterjee and K. J. Irgolic, Anal. Commun., 1998, 35, 337-340.

12 F. Li, W. Goessler and K. J. Irgolic, Anal. Commun., 1998, 35, 361364.

13 H. Mendez, I. Lavilla and C. Bendicho, J. Anal. At. Spectrom., 2004, 19, 1379-1385.

14 H. Tao, J. W. H. Lam and J. W. McLaren, J. Anal. At. Spectrom., 1993, 8, 1067-1073.

15 C. Moor, J. W. H. Lam and R. E. Sturgeon, J. Anal. At. Spectrom., 2000, 15, 143-149.

16 P. C. Uden, H. T. Boakye, C. Kahakachchi, R. Hafezi, R. Nolibos, E. Block, J. Sherida and J. F. Tyson, J. Anal. At. Spectrom., 2004, 19, 65-73.

17 Z. Zhang, S. Chen, H. Yu, M. Sun and W. Liu, Anal. Chim. Acta, 2004, 513, 417-423.

18 L. D. Martinez, M. Baucells, E. Pelfort, M. Roura and R. Olsina, Fresenius' J. Anal. Chem., 1997, 357, 850-852.

19 L. D. Martinez, E. Saidman, E. Marchevsky and R. Olsina, J. Anal. At. Spectrom., 1997, 12, 487-490.

20 J. Stripeikis, M. Tudino, O. Troccoli, R. Wuilloud, R. Olsina and L. Martinez, Spectrochim. Acta, Part B, 2001, 56, 93-100.

21 S. Moyano, R. G. Wuilloud, R. A. Olsina, J. A. Gasquez and L. D. Martinez, Talanta, 2001, 54, 211-219.

22 E. J. dos Santos and E. de Oliveira, Braz. Arch.Biol. Technol., 2001, 44, 233-238.
23 P. Pohl, Trends Anal. Chem., 2004, 23, 87-101.

24 E. J. dos Santos, A. B. Herrmann, V. L. A. Frescura and A. J. Curtius, Anal. Chim. Acta, 2005, 548, 166-173.

25 R. Rubio, A. Padro and G. Rauret, Anal. Chim. Acta, 2005, 353, 91-97.

26 N. Carrion, M. Murillo and D. Diaz, Spectrochim. Acta, Part B, 2003, 58, 1375-1389.

27 I. Rojas, M. Murillo, N. Carrion and J. Chirinos, Anal. Bioanal. Chem., 2003, 376, 110-117.

28 R. L. J. McLaughlin and I. D. Brindle, J. Anal. At. Spectrom., 2002, 17, 1540-1548.

29 E. H. Evans, J. A. Day, A. Fisher, W. J. Price, C. M. M. Smith and J. F. Tyson, J. Anal. At. Spectrom., 2004, 19, 775-812.

30 B. D. Wake, A. R. Bowie, E. C. V. Butler and P. R. Haddad, Trends Anal. Chem., 2004, 23, 491-500.

31 J. L. Gomez-Ariza, J. A. Pozas, I. Giraldez and E. Morales, Analyst, 1999, 124, 75-78.

32 T. Kubota and T. Okutani, Anal. Chim. Acta, 1997, 351, 319.

33 U. Ornemark and A. Olin, Talanta, 1994, 41, 67.

34 P. E. Carrero and J. F. Tyson, Analyst, 1997, 122, 915-919.

35 C. Lu, X. Yan, Z. Zhang, Z. Wang and L. Liu, J. Anal. At. Spectrom., 2004, 19, 277-281.

36 K. Abbas-Ghaleb, N. Gilon, G. Cretier and J. M. Mermet, Anal. Bioanal. Chem., 2003, 377, 1026-1031.

37 M. Bueno and M. Potin-Gautier, J. Chromatogr. A, 2002, 963, 185-193.

38 D. Wang, G. Alfthan and A. Aro, Environ. Sci. Technol., 1994, 28, 383.

39 S. G. Offley, N. J. Seare, J. F. Tyson and H. A. B. Kibble, J. Anal. At. Spectrom., 1991, 6, 133-138.

40 S. Moyano, J. A. Gasquez, E. Marchevsky, R. Olsina and L. D. Martinez, At. Spectrosc., 1997, 18, 152-155.

41 A. E. A. Werner, Analyst, 1940, 65, 286.

42 J. S. Becker, Can. J. Anal. Sci. Spectrosc., 2002, 47, 98-108.

43 S. Greenfield, M. S. Salman, M. Thomsen and J. F. Tyson, J. Anal. At. Spectrom., 1989, 4, 55-65. 